ABDI: Jurnal Pengabdian dan Pemberdayaan Masyarakat ISSN: 2656-369X (Print), 2684-8570 (Online)

Volume 3 No. 2, Desember 2021

http://abdi.ppj.unp.ac.id/index.php/abdi

Email: abdi@ppj.unp.ac.id

DOI: https://doi.org/10.24036/abdi.v3i2.165

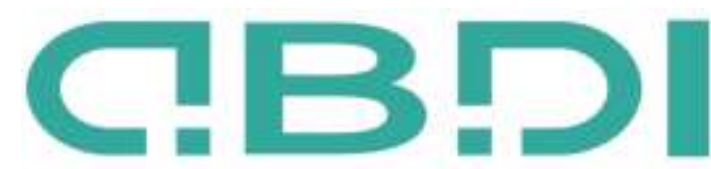

ABDE JURNAL PENGABOIAN DAN PEMBERDAYMN MUSYARAKAT

\title{
Pemberdayaan Aparatur Pemerintahan Nagari Melalui Literasi Digital Anti-Hoaks dan Penguatan Ketahanan Informasi Nagari
}

\author{
Irwan Irwan', Alia Azmi², Rizki Syafril ${ }^{3}$, Monica Tiara ${ }^{4}$ \\ ${ }^{1,2,4}$ Prodi Pendidikan Pancasila dan Kewarganegaraan, Universitas Negeri Padang \\ ${ }^{3}$ Prodi Ilmu Administrasi Negara, Universitas Negeri Padang
}

E-mail: irwanhamdi@ fis.unp.ac.id

\begin{abstract}
Abstrak
Penguatan Ketahanan Informasi bagi aparatur pemerintahan menjadi hal yang urgent saat sekarang ini sebab sebagai abdi masyarakat, aparatur pemerintahan dituntut untuk dapat memberikan informasi dan melayani masyarakat dengan optimal. Salah satunya dengan penyampaian informasi yang valid dan jauh dari hoaks yang dapat meresahkan masyarakat. Oleh karena itu, tim pengabdi dari Program studi PPKn melaksanakan kegiatan pemberdayaan aparatur pemerintahan nagari melalui literasi digital anti hoaks. Pengabdian ini dilaksanakan di Nagari Panampung Kecamatan Ampek Angkek Kabupaten Agam. Metode kegiatannya yaitu: (1) Peningkatan dan pengetahuan aparatur nagari terkait dengan informasi-informasi yang tergolong hoaks, serta bahayanya jika beredar di masyarakat; (2) Peningkatan pengetahuan aparatur nagari tentang literasi digital; (3) Identifikasi strategi dan langkah-langkah untuk menghindari dan melawan informasi hoaks demi menciptakan ketahanan informasi nagari; (4) Strategi dan evaluasi terhadap keberlanjutan program. Implikasi dari kegiatan ini yaitu terciptanya ketahanan informasi bagi segenap aparatur Nagari Panampung yang bermuara pada tata kelola pemerintahan yang baik (good corporate governance).
\end{abstract}

Kata kunci: ketahanan informasi, literasi digital, anti-hoaks, Nagari Panampuang

\section{Abstract}

Strengthening Information Security for government officials is an urgent matter at this time because as public servants, government officials are required to be able to provide information and serve the community optimally. One of them is the delivery of valid information and far from hoaxes that can disturb the public. Therefore, the service team from the PPKn study program carried out empowerment activities for the nagari government apparatus through anti-hoax digital literacy. This service was carried out in Nagari Panampuang, Ampek Angkek District, Agam Regency. The methods of its activities are: (1) Increasing and knowledge of the nagari apparatus related to information classified as hoaxes, as well as the dangers if circulated in the community; (2) Increasing the knowledge of the nagari government on digital literacy; (3) Identify strategies and steps to avoid and fight hoax information in order to create information security in the nagari; and (4) Strategy and evaluation of program sustainability. The implication of this activity is the creation of information security for all Nagari Panampuang apparatus which leads to good corporate governance.

Keyword: personal resilience, digital literacy, anti-hoax, Panampuang

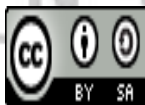




\section{Pendahuluan}

Nagari Panampuang merupakan salah satu dari tujuh nagari yang berada di Kecamatan Ampek Angkek Kabupaten Agam. Nagari dengan luas sekitar 6,8 kilometer persegi ini dihuni oleh sekitar 9 ribu jiwa (berdasarkan data nagari tahun 2018). Nagari Panampung merupakan salah satu nagari yang berlokasi dekat dengan Kota Bukittinggi dan berada di jalur utama lintas Sumatera Barat-Riau. Lokasinya yang berada dekat dengan Kota Bukittinggi menjadikan daerah ini sebagai salah satu kawasan strategis penyangga kota. Nagari ini dihuni oleh warga asli dan pendatang yang bekerja di Bukittinggi dan memilih tinggal dengan menyewa rumah dan kamar kos.

Lokasi nagari yang dekat dengan kota juga menguntungkan dari segi aksesibilitas jaringan internet. Seluruh Kawasan nagari telah terjangkau oleh koneksi internet dengan kecepatan yang baik. Selain itu jaringan internet kabel juga sudah masuk ke Kawasan-kawasan strategis di sini seperti sekolah dasar dan menengah. Kondisi ini sangat menguntungkan warga nagari yang mayoritas telah memiliki telepon genggam. Aksesibilitas dan pencarian segala bentuk informasi mudah dilakukan. Misalnya saat kebijakan belajar dari rumah selama Pandemi Covid-19 yang telah diatur pemerintah dapat berjalan dengan baik. Seperti pisau bermata dua, ketersediaan jaringan internet yang memadai dapat menjadi ancaman bagi pengguna karena media digital sangat rentan disusupi oleh informasi-informasi yang tidak benar atau belum tentu kebenarannya. Situasi seperti ini perlu menjadi perhatian khusus dan jangan abai akan dampak jangka panjangnya.

Dari hasil pengamatan, terdapat beberapa informasi hoaks yang pernah terjadi di Nagari Panampung. Salah satunya hoaks terkait dampak Pandemi Covid-19 yang juga telah menimbulkan kecemasan di tengah masyarakat. Begitu juga dengan informasi hoaks terkait bantuan-bantuan penanganan Covid-19 yang berasal dari pihak yang tidak bertanggung jawab. Selain itu bertepatan dengan momentum pemilihan wali nagari (Pilwanag), beredarnya informasi hoaks juga tidak dapat dibendung. Terdapat beberapa informasi yang beredar di masyarakat yang mendukung atau menyudutkan calon-calon tertentu. Kondisi ini mengingatkan kita pada masa Pilpres dan Pileg di Indonesia, namun dalam kerangka yang lebih kecil. Masyarakat yang majemuk dan didukung oleh ketersediaan internet dan jaringan yang baik membuat arus informasi menyebar begitu cepat. Hal ini berimplikasi pada semakin banyak informasi yang dibutuhkan (Rachmawati, Winoto, \& Rohman, 2018). Masyarakat nagari akan rentan disusupi oleh informasi-informasi hoaks dari pihak yang tidak bertanggung jawab. Penyebaran informasi hoaks jika tidak dapat disaring secara cerdas akan melemahkan ketahanan informasi masyarakat. Gejala dari lemahnya ketahanan informasi masyarakat yaitu: tidak mampu membedakan kebenaran suatu informasi; mudah terprovokasi; cenderung emosional; dan mudah menyalahkan orang lain. Kondisi ini jika dibiarkan tanpa ada penanganan dapat menyulut konflik internal masyarakat nagari. Apalägi nagari Panampung sering didatangi warga dari luar, tentu ini menjadi urgen untuk diselesaikan. Kemudian bagi aparatur nagari khususnya, beredarnya informasi hoaks akan mengganggu jalannya pemerintahan nagari dan menghambat proses pembangunan di nagari. Suatu daerah yang terus menerus diterpa isu hoaks akan melemahkan ketahanan informasinya. Potensi bahaya berita dan informasi hoaks yang seperti bom waktu yang akan merusak sendi-sendi kehidupan masyarakat dan melemahkan ketahanan nasional. Oleh karena itu perlu ada solusi konkrit untuk memutus mata rantai penyebaran informasi hoaks tersebut yaitu peningkatan budaya literasi di tengah masyarakat untuk mewujudkan smart citizen dan penguatan kompetensi literasi digital aparatur nagari untuk mewujudkan ketahanan informasi. Kegiatan dilaksanakan melalui beberapa program diantaranya melalui paparan materi, penyebaran angket, diskusi, dan Focus Group Discussion.

\section{Metode Pelaksanaan}

Metode pelaksanaan kegiatan pengabdian ini terdiri dari beberapa tahap. Pertama, Expos (Montessori, Dewi, \& Tiara, 2020), yaitu internalisasi pemahaman dan penguatan tentang literasi digital anti hoaks untuk mewujudkan smart citizen. Fokus kegiatan ini adalah pemberian pengetahuan dan pemahaman kepada peserta. 
Kedua, kegiatan analisis kasus dimana melalui metode ini peserta di ajak untuk menganalisis kasus-kasus hoaks di media sosial secara umum dan khususnya menyangkut kondisi di nagari, serta dampak yang ditimbulkan. Kegiatan Ketiga yaitu identifikasi dan analisis dokumen tentang literasi digital anti-hoaks wilayah nagari. Kegiatan selanjutnya yaitu mengidentifikasi langkah-langkah yang diperlukan dalam menghindari informasi hoaks dan meningkatkan ketahanan informasi yang dipandu oleh instruktur dan narasumber. Sebagai muara dari kegiatan ini yaitu adanya rumusan komitmen meningkatkan literasi digital dan melawan hoaks melalui penulisan semboyan dan atau penandatanganan petisi, mading anti-hoaks dan bentuk lain sesuai kesepakatan dengan nagari. Datadata dikumpulkan melalui observasi, workshop, Focus Group Discussion (FGD) dan angket. Responden terdiri dari perangkat nagari, wali jorong se-Nagari Panampung, Ketua KAN beserta anggota, Ketua Bamus beserta anggota, PKK, Parik Paga, dan perwakilan lembaga-lembaga nagari lainnya di lingkungan nagari Panampung.

\section{Hasil dan Pembahasan}

\subsection{Peningkatan Budaya Literasi Masyarakat untuk Mewujudkan Smart Citizen}

Penguatan Ketahanan Informasi di nagari perlu dimulai dari peningkatan budaya literasi di tengah masyarakat. Budaya literasi mencakup kemampuan membaca, menulis dan memahami informasi sehingga mampu memastikan kebenaran dari informasi tersebut. Kegiatan membaca dan menulis sejatinya merupakan bagian paling mendasar dari sekian banyak kegiatan yang dilakukan manusia. Sebab, tanpa membaca dan menulis mereka akan ketinggalan informasi-informasi penting (Nugraha, 2017). Dewasa ini pemaknaan literasi telah meluas dari sekedar membaca dan menulis. Permatasari di dalam artikelnya justru memperluas makna literasi kepada penguasaan teknologi dan informasi, mampu berfikir kritis, peka terhadap lingkungan bahkan kepekaan terhadap politik (Afrina, Adripen, Eliwatis, Rikarno, \& Hanafi, 2020). Hal ini sebagai imbas dari masifnya perkembangan teknologi dan informasi di dunia sehingga memperluas makna literasi lebih dari sekedar membaca dan menulis. Indonesia masih memiliki pekerjaan rumah besar untuk menggiatkan literasi di tengah masyarakat. Kegiatan membaca dan menulis selama ini belum menjadi kebiasaan dan masih dianggap kegiatan sampingan untuk sekedar mengisi waktu. Hal ini yang ditekankan oleh narasumber dalam kegiatan workshop.

Workshop literasi yang mengangkat tema peningkatan budaya literasi di tengah masyarakat mendatangkan narasumber pakar Pendidikan dari Prodi PPKn Fakultas Ilmu Sosial yaitu Dr. Maria Montessori, M.Ed, M.Si. Sesuai dengan tema yang diberikan, narasumber memulai paparan dengan fakta-fakta tentang rendahnya tingkat literasi di Indonesia jika dibandingkan dengan negara-negara tetangga. Kemudian dilanjutkan dengan dampak-dampak negatif jika budaya literasi dalam diri menjadi hilang seiring dengan teknologi digital yang masih mencengkeram khususnya bagi generasi muda. Pada bagian akhir paparan, Dr. Maria Montessori, M.Ed, M.Si. memberikan strategi-strategi yang dapat diterapkan dalam menumbuhkan maupun menyegarkan kembali budaya literasi di tengah masyarakat. Pada sesi diskusi, para peserta juga tertarik mengelaborasi strategi tersebut yang disesuaikan dengan situasi dan kondisi masyarakat di nagari Panampung.

Pembudayaan literasi bagi aparatur nagari dan lembaga-lembaga pemerintahan menjadi penting karena sejatinya budaya literasi tidak dapat dipisahkan dengan aspek politik dan pemerintahan. Munir (2019) mengungkapkan bahwa budaya membaca seseorang dapat meningkatkan wawasan dan mengetahui keadaan ekonomi, sosial, budaya dan keagamaan sekitar (Munir \& Hidayatullah, 2019). Budaya literasi tidak akan tercipta tanpa ada dorongan dari pemerintahnya bagi dari sisi finansial maupun dukungan immaterial. Permatasari dalam artikelnya juga menyebutkan bahwa masih sedikit pemerintah daerah yang benar-benar peduli akan budaya literasi bagi masyarakat. Masalah literasi dianggap tidak menjadi prioritas jika dibandingkan dengan infrastruktur dan pembangunan sector ekonomi. Hal ini tentu akan berdampak pada minimnya anggaran untuk penyediaan pojok-pojok literasi bagi masyarakat (Sutrisna, 2020). Isu ini juga dipaparkan oleh narasumber, sebab sejatinya aparatur pemerintahan nagari memiliki peran ganda yakni sebagai orang tua dan sebagai pelayan masyarakat yang tindak tanduknya menjadi cerminan masyarakat yang dipimpinnya. 
Perlu kiranya komitmen Bersama untuk memperbaiki tingkat literasi masyarakat demi perbaikan sumberdaya manusia. Sebab, budaya literasi sangat berkontribusi dalam menciptakan warga negara yang cerdas, sehingga menjadi cikal bakal bangsa yang berkualitas (Permatasari, 2015).

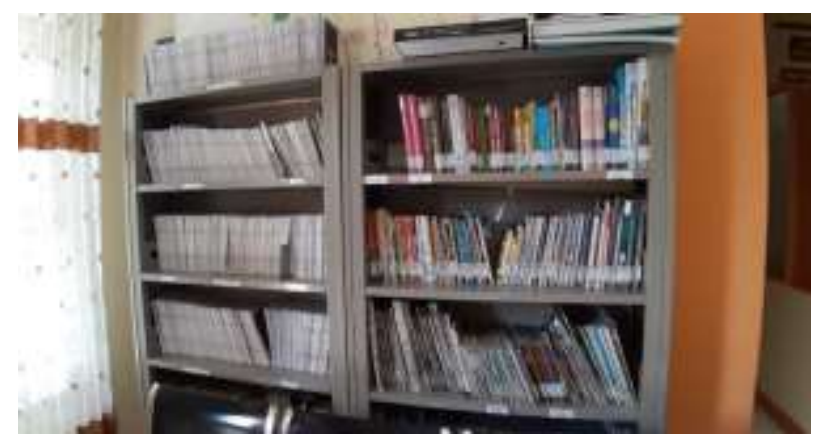

Gambar 1. Pojok Literasi Nagari di Kantor Wali Nagari Panampuang

Gambar 1 menunjukkan bahwa di kantor Wali nagari Panampung sudah tersedia pojok literasi yang dapat digunakan oleh masyarakat saat menunggu pelayanan aparatur. Namun, sangat sedikit yang memanfaatkan lokasi tersebut untuk membaca. Masyarakat masih memilih telepon genggam dan media sosial untuk mengisi waktu sembari menunggu proses pelayanan oleh aparatur nagari.

\subsection{Penguatan Kompetensi Literasi Digital Aparatur Nagari untuk Mewujudkan Ketahanan Informasi}

Penguatan kompetensi literasi digital merupakan program selanjutnya yang perlu mendapatkan perhatian serius. Hague di dalam Kurnianingsih, dkk, menyatakan bahwa literasi digital merupakan kemampuan dalam membuat, berbagi, dan berkomunikasi secara efektif serta memahami kapan penggunaan teknologi untuk menunjang hal tersebut (Kurnianingsih, Rosini, \& Ismayati, 2017). Seperti yang kita amati sehari-hari, kita tidak bisa lepas dari peran teknologi informasi dan digitalisasi terutama dalam memberikan pelayanan masyarakat. Teknologi telah membantu operasional pekerjaan menjadi lebih efektif dan efisien. Sebab penggunaan teknologi informasi digital telah mengurangi penggunaan sumber daya dan memangkas waktu untuk mengevaluasi, mengumpulkan, dan menyampaikan informasi kepada publik (Kurnianingsih et al., 2017). Hal ini yang mendasari pentingnya penguatan kompetensi literasi digital bagi aparatur nagari Panampung sebagai penyambung lidah masyarakat di struktur nagari atau desa.

Materi disampaikan oleh Rahmadani Yusran, S.Sos, M.Si yang merupakan dosen jurusan Ilmu Administrasi Negara dan memahami bidang teknologi informasi digital dengan baik. Paparan diawali dengan tampilan data-data statistik tentang perkembangan digitalisasi di dunia dan di Indonesia. Dimana pengguna aktif internet di Indonesia menunjukkan angka yang cukup tinggi seperti terlihat pada Gambar 2 yang merupakan salah satu paparan narasumber:

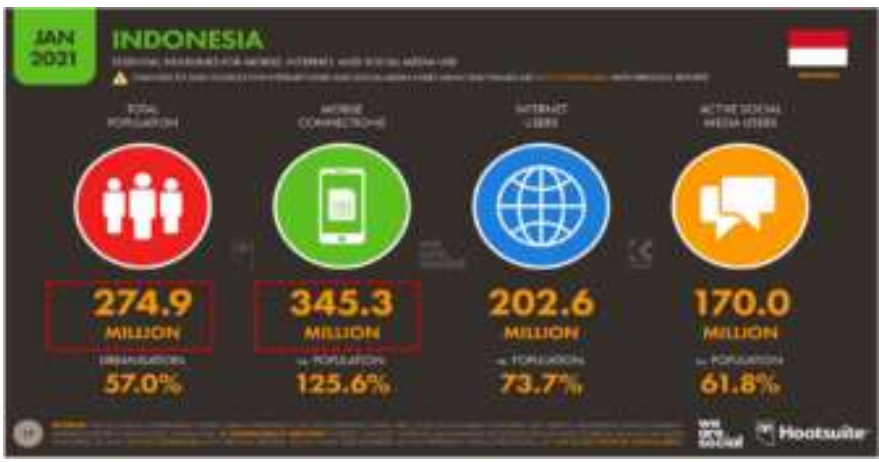

Gambar 2. Data pengguna Aktif Media Sosial di Indonesia

Sumber: hootsuite-we-are-social-indonesian-digital-report-2021 
Data pada Gambar 2 menunjukkan hasil yang mengejutkan bahwa pengguna koneksi seluler di Indonesia justru melebihi total populasi dengan hasil $125.6 \%$ dari total populasi Indonesia. Ini berarti tiap satu orang penduduk memiliki lebih dari satu koneksi selular pada perangkat elektroniknya. Kemudian $73.7 \%$ populasi Indonesia adalah pengguna aktif koneksi internet. $61.8 \%$ penduduk menggunakan internet untuk kebutuhan media sosial sehari-hari. Data yang dirilis pada Januari 2021 diatas semakin memperkuat argument bahwa penggunaan perangkat teknologi informasi di Indonesia semakin hari semakin pesat dan meningkat. Seiring dengan kebijakan digitalisasi pemerintah dan komitmen untuk menyediakan jaringan internet hingga ke pelosok-pelosok daerah di Indonesia.

Kemudian penggunaan media sosial melalui platform-platform digital yang telah menjadi media komunikasi dan interaksi utama saat ini. Beberapa diantaranya sangat mendominasi yakni WhatsApp, Facebook, Instagram, Telegram, dan Twitter, seperti terlihat pada gambar dibawah ini. Daya yang juga dirilis pada Januari 2021, memperlihatkan bahwa platform Facebook, WhatsApp, Messenger, dan Instagram menjadi aplikasi dengan penggunaan tertinggi di dunia. Hal tersebut tentu tidak berbeda signifikan dengan di Indonesia. Dimana dari beberapa survei dan penelitian justru menunjukkan pengguna media sosial Indonesia menjadi salah satu yang tertinggi di Indonesia. Data yang dirilis media Kompas menunjukkan pengguna media sosial di Indonesia meningkat 15.5\% pada tahun 2021 ini menjadi $73.7 \%$ dari total populasi.

Berdasarkan data diatas maka dirasa perlu memberikan materi mengenai literasi digital terhadap aparatur pemerintahan nagari. Hal ini bertujuan agar masyarakat khususnya aparatur pemerintahan tidak hanya sebagai konsumen dari produk teknologi informasi tapi dapat memahami dampak negatif yang timbul di kemudian hari jika media sosial disalahgunakan untuk menyebarkan segala bentuk informasi. Keterbukaan media sosial rentan disusupi oleh informasi bohong atau hoaks. Perlu kemampuan dalam menyaring segala bentuk informasi hoaks agar tidak meresahkan di tengah masyarakat. Ini menjadi stressing point dalam materi narasumber kedua.

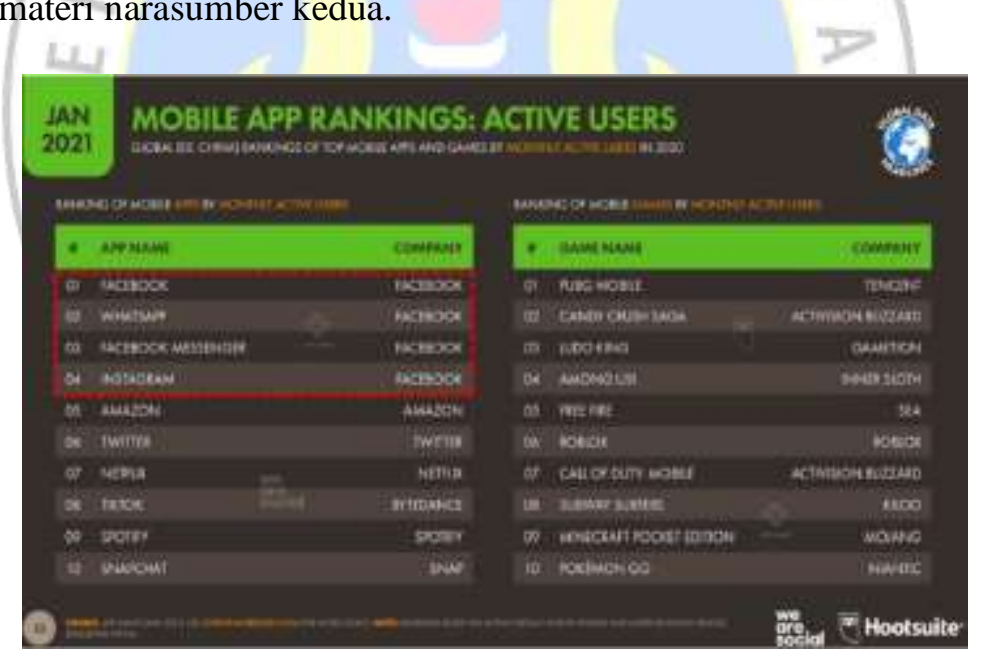

Gambar 3. Peringkat Pengguna Media Sosial Aktif di Dunia

Sumber: hootsuite-we-are-social-indonesian-digital-report-2021

Senada dengan narasumber pertama, paparan materi oleh narasumber kedua ini berlangsung sekitar satu setengah jam yang diawali dengan pada materi kemudian sesi diskusi bersama para peserta. Para peserta yang merupakan aparatur nagari dari berbagai lintas usia terlihat sangat antusias karena memang topik yang dibahas sangat dekat dengan keseharian masyarakat yang tidak pernah lepas dari penggunaan gadget dan media sosial dalam interaksi sehari-hari. Sebagai penutup pada sesi kedua ini, tim pengabdi membagikan angket yang berisi beberapa butir pertanyaan tentang pengetahuan peserta mengenai literasi digital dan upaya-upaya yang telah dilakukan dalam menghambat penyebaran informasi hoaks di tengah masyarakat nagari Panampuang. 


\section{Kesimpulan}

Dari pelaksanaan pengabdian yang telah dielaborasi di atas, maka dapat disimpulkan beberapa hal terkait penguatan literasi digital bagi aparatur pemerintahan di Nagari Panampuang. Penguatan budaya literasi dan literasi digital di tengah masyarakat perlu ditingkatkan terutama bagi abdi negara pelayan masyarakat. Sebab dengan demikian maka setiap orang akan mampu menyaring segala bentuk informasi yang beredar dan belum tentu kebenarannya. Para peserta sangat antusias dengan paparan materi narasumber dan berharap kegiatan ini dapat dilanjutkan. Oleh karena itu, berdasarkan hasil evaluasi dan masukan dari masyarakat, untuk selanjutnya tim pengabdi akan membantu aktivasi website nagari yang sempat terhenti dan tidak dapat diakses. Hal ini menjadi hal pokok agar segala bentuk informasi nagari tidak beredar secara simpang siur. Aktivasi website nagari akan diiringi dengan komitmen Bersama aparatur pemerintahan nagari dan Lembaga-lembaga nagari untuk Bersama-sama memerangi berita hoaks di tengah masyarakat.

\section{Daftar Pustaka}

Afrina, C., Adripen, A., Eliwatis, E., Rikarno, R., \& Hanafi, B. P. (2020). Pemberdayaan Komunitas Taman Baca Masyarakat Dalam Peningkatan Literasi Informasi di Nagari Tabek. Batoboh, 5(1), 46-55.

Kurnianingsih, I., Rosini, R., \& Ismayati, N. (2017). Upaya Peningkatan Kemampuan Literasi Digital Bagi Tenaga Perpustakaan Sekolah dan Guru di Wilayah Jakarta Pusat Melalui Pelatihan Literasi Informasi. Jurnal Pengabdian Kepada Masyarakat, 3(1), 61-76.

Montessori, M., Dewi, S. F., \& Tiara, M. (2020). Membangun Kesadaran Anti Korupsi Aparatur Pemerintahan Nagari. ABDI: Jurnal Pengabdian Dan Pemberdayaan Masyarakat, 2(2).

Munir, S., \& Hidayatullah, A. (2019). Peran Taman Bacaan Masyarakat (TBM) dalam Meningkatkan Minat dan Budaya Baca di Kabupaten Ciamis. Jurnal Literasi, 3(1), 23-29.

Nugraha, M. T. (2017). Budaya Literasi Dan Pemanfaatan Sosial Media Pada Masyarakat. Jurnal Pemikiran Pendidikan Islam At-Turats, 11(2), 124-132.

Permatasari, A. (2015). Membangun Kualitas Bangsa Dengan Budaya Literasi. Prosiding Seminar Nasional Bulan Bahasa 2015. FKIP Universitas Bengkulu.

Rachmawati, T. S., Winoto, Y., \& Rohman, A. S. (2018). Studi Tentang Pemetaan Budaya Literasi Informasi pada Masyarakat Pesisir Selatan Jawa Barat. Record and Library Journal, 4(1).

Sutrisna, I. P. G. (2020). Gerakan Literasi Digital Pada Masa Pandemi Covid-19. Stilistika: Jurnal Pendidikan Bahasa Dan Seni, 8(2), 268-283. 